\title{
Factors affecting growth of Legionella pneumophila in liquid media
}

\author{
J. BARKER, I. D. FARRELL AND J. G. P. HUTCHISON
}

Regional Public Health Laboratory, East Birmingham Hospital, Birmingham B9 5ST

\begin{abstract}
Summary. The growth in liquid media of Legionella pneumophila serogroups 1-6 was monitored turbidimetrically and factors affecting growth rate were studied. The presence of inhibitors, use of detoxifying agents and the method of broth preparation each had significant effects on cultivation. Cysteine was essential for growth; the optimal concentration was $100 \mu \mathrm{g} / \mathrm{ml}$, but supplemental iron had no demonstrable effect.
\end{abstract}

\section{Introduction}

Many factors affect the growth of Legionella spp. in vitro. Legionellae are reported not to grow on $5 \%$ horse-blood agar unless it is enriched with ferric pyrophosphate and L-cysteine (Greaves, 1980). Edelstein (1981) found that a charcoal-yeast extract agar containing iron and cysteine with added $\alpha$ ketoglutarate supported the growth of most strains of Legionella pneumophila. Ristroph et al. (1980) showed the importance of charcoal in heat-sterilised medium-a heat-sterilised yeast extract broth (without added charcoal) did not support the growth of legionellae whereas the same medium, sterilised by membrane filtration, supported growth without charcoal treatment. Most broth media do not support growth of legionellae.

In this investigation, yeast-extract broths were prepared by various methods in attempts either to avoid the production of toxic components during preparation or to neutralise their effects. The growth of legionellae was monitored turbidimetrically, with estimations of the viable counts at appropriate times. The requirement for supplemental ferric pyrophosphate and L-cysteine was also studied.

\section{Materials and methods}

\section{Bacterial strains}

Twenty strains of $L$. pneumophila were used, representing serogroups $1-6$, isolated from clinical and environmental samples. The strains were grown on Buffered Charcoal-Yeast Extract (BCYE) agar and were suspended in BCYE broth at a concentration of $c .10^{10} \mathrm{cfu} / \mathrm{ml}$ and stored at $-70^{\circ} \mathrm{C}$. When required, the stored strains

Received 3 Mar. 1985; revised version accepted 30 Oct. 1985. were re-cultured on BCYE agar and the inoculum prepared as described below.

\section{Media}

$B C Y E$ broth was prepared as described by Edelstein (1981). Yeast extract powder $10 \mathrm{~g}$, activated charcoal (Norit A) $1.5 \mathrm{~g}$, plus the Analar-grade chemicals, ACES buffer (Sigma) $10 \mathrm{~g}, \alpha$ ketoglutarate monopotassium salt $1 \mathrm{~g}$ and potassium hydroxide $2.8 \mathrm{~g}$, were made up in $1 \mathrm{~L} \mathrm{of}$ distilled water. After sterilising at $121^{\circ} \mathrm{C}$ for $15 \mathrm{~min}$, Analar-grade L-cysteine hydrochloride $0.4 \mathrm{~g}$ and ferric pyrophosphate $0.25 \mathrm{~g}$ were added and the $p \mathrm{H}$ of the medium was adjusted to $6.9 \pm 0.5$ at $40^{\circ} \mathrm{C}$. The charcoal was sedimented by centrifugation and the supernate used as BCYE broth for the growth studies.

$B C Y E$ agar was made according to the above formulation but without removing the charcoal and with the addition of agar (Difco) $12 \mathrm{~g} / \mathrm{L}$.

A series of growth studies was performed with several yeast-extract broths (YEB) prepared with the same constituents as were incorporated in BCYE (above), except that charcoal was excluded and, in two of the modifications, the yeast extract component was pretreated to remove potential growth inhibitors.

$Y E B \quad 1$ was prepared exactly as for BCYE broth (including sterilisation by autoclaving at $121^{\circ} \mathrm{C}$ for 15 min), except that charcoal was not added.

$Y E B 2$ was made without heat-sterilization of ingredients and without added charcoal. The resulting broth was sterilised by filtration through a $0.45 \mu \mathrm{m}$ cellulose membrane filter.

$Y E B$ 3. The dry yeast-extract powder was shaken in a separating funnel with approximately 10 times its weight of ether; the washings were discarded and the powder dried of all solvent. It was then incorporated with the other BCYE ingredients, except charcoal, into a broth that was autoclaved at $121^{\circ} \mathrm{C}$ for $15 \mathrm{~min}$.

$Y E B$ 4. The yeast extract $(10 \mathrm{~g})$ was made up with 100 $\mathrm{ml}$ of distilled water, transferred to a 'visking tube bag' and dialysed at $4^{\circ} \mathrm{C}$ against distilled water for $24 \mathrm{~h}$. It was 
then added to the other BCYE constituents, except charcoal, and the resulting broth heat sterilised as above.

$Y E B 5$ was the clear pale straw-coloured fluid exuded from the gel phase of bottled BCYE agar slopes, after they had been stored at $4 \mathrm{C}$ for 5 days. About $1 \mathrm{ml}$ of the fluid ('syneresis fluid') was obtained from each $10 \mathrm{ml}$ slope.

\section{Inoculum}

A suspension in distilled water, at $c .10^{8} \mathrm{cfu} / \mathrm{ml}$, was made from a 3-day L. pneumophila culture grown at $37^{\circ} \mathrm{C}$ on BCYE agar. A $20-\mu 1$ inoculum of the suspension was added to $1 \mathrm{ml}$ of each test broth, giving an initial concentration in the broth of $c .10^{6} \mathrm{cfu} / \mathrm{ml}$.

\section{Growth curves}

These were determined turbidimetrically with the Abbott MS-2 Research System, which records changes in optical density (O.D.) in broth cultures every $5 \mathrm{~min}$ for up to $35 \mathrm{~h}$ and then computes the growth curves. The experiments were set up in cartridges consisting of 11 cuvettes, each holding $1 \mathrm{ml}$ of broth; after inoculation they were incubated at $37 \mathrm{C}$ in the incubator module of the equipment.

\section{Results}

Typical growth curves, obtained $30 \mathrm{~h}$ after inoculation of test broths (YEB 1-5) with a strain of $L$. pneumophila serogroup 1, are shown in fig 1. All the twenty L. pneumophila strains tested, representing serogroups $1-6$, showed similar growth patterns. In both BCYE broth and YEB 5 ('syneresis fluid') there was an initial increase in optical density at $15 \mathrm{~h}$ and thereafter an exponential increase. After $30 \mathrm{~h}$ the viable count was $1.5 \times 10^{10} \mathrm{cfu} / \mathrm{ml}$. Examination of the broth culture at the end of the growth period with phase contrast microscopy showed rods $0 \cdot 5-1$ $\mu \mathrm{m}$ in width and $2-c .8 \mu \mathrm{m}$ in length. A few filamentous forms $c$. $30-40 \mu \mathrm{m}$ in length were seen in the 30-h culture, but not in the 15-h culture.

None of the strains of Legionella grew within the $30 \mathrm{~h}$ incubation period in the heat-sterilised broth without added charcoal (YEB 1). However, when charcoal was subsequently added to this broth, multiplication of legionellae took place after incubation for a further $15 \mathrm{~h}$. Growth of legionellae was first detected turbidimetrically after incubation for $26 \mathrm{~h}$ in YEB 4 broth (heat-sterilised, but with

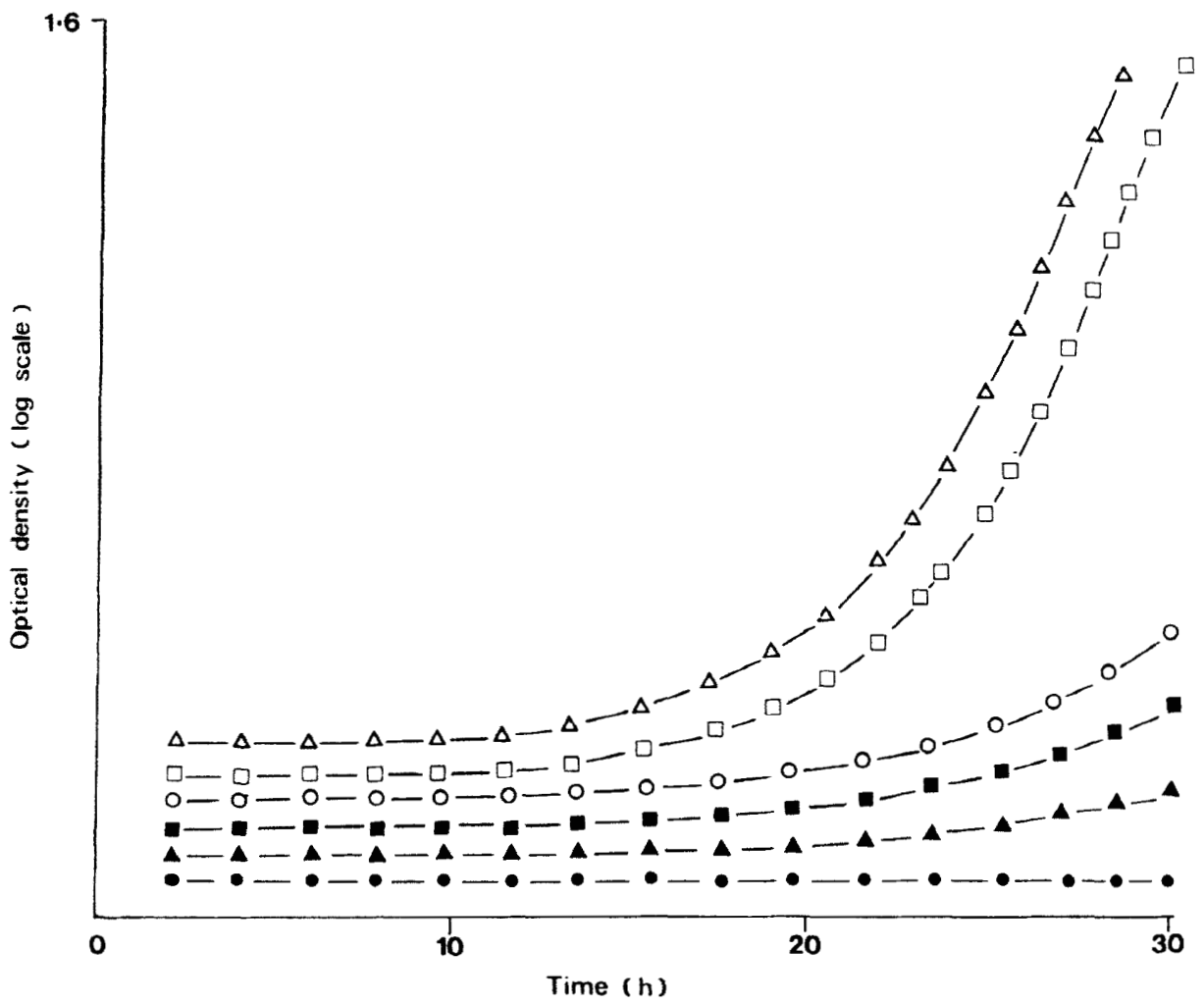

Fig. 1. Growth of L. pneumophila, serogroup 1, in six broths: $-\bullet$, YEB l (autoclaved);

, YEB 2 (filtered); O-O, YEB 3 (ether treated); $\triangle$, YEB 4 (dialysed): $\square-\square$, YEB 5 (syneresis liquid); $\triangle-\triangle$, control (BCYE broth). The origin of each curve has been expanded up the ordinate limb of the graph for clarity. 
dialysed yeast extract); the viable count after incubation for $30 \mathrm{~h}$ was $8.5 \times 10^{7} \mathrm{cfu} / \mathrm{ml}$. Similar growth was obtained in YEB 2 broth (sterilised by membrane filtration) and in YEB 3 (heat-sterilised, but with ether-treated yeast extract). Strains grown in BCYE broth usually gave a detectable increase in optical density after an apparent lag phase of $c .15 \mathrm{~h}$. At that stage the viable count was $c .2 .5 \times 10^{7} \mathrm{cfu} /$ $\mathrm{ml}$, representing approximately a 10 -fold increase over that of the initial inoculum, and a faint turbidity could be seen by visual inspection.

\section{Growth promoters and inhibitors}

To portions of YEB 1 (heat-sterilised broth) were added either $\mathrm{H}_{2} \mathrm{O}$-lysed horse red-blood cells (previously washed in saline) $2 \% \mathrm{v} / \mathrm{v}$, or soluble starch $0.15 \% \mathrm{w} / \mathrm{v}$. A further portion was shaken with activated charcoal $0.15 \% \mathrm{w} / \mathrm{v}$ and then centrifuged to give a clear broth. These test broths $(1 \mathrm{ml})$ and an untreated control broth, were each inoculated with $10^{6} \mathrm{cfu}$ of a strain of L. pneumophila serogroup 1 and incubated at $37^{\circ} \mathrm{C}$. The charcoal-treated and starch-treated broths produced typical growth curves (as for BCYE broth in fig. 1) with an exponential phase detected turbidmetrically at $c$. $16 \mathrm{~h}$ and $20 \mathrm{~h}$, respectively. The lysed-blood broth culture gave no detectable opacity change until $25 \mathrm{~h}$ and the control gave none at all within $30 \mathrm{~h}$. This effect was attributable to the horse red-cell lysate rather than any plasma or serum present, because the effect could not subsequently be duplicated with serum or plasma alone.

\section{Inhibitory effect of sodium chloride}

$\mathrm{NaCl}$ is known to inhibit L. pneumophila (Edelstein and Meyer 1984). We tested a series of BCYE broths containing increasing concentrations of $\mathrm{NaCl}$ and found that growth was inhibited at $0.03 \%$ $\mathrm{w} / \mathrm{v}$ or greater. Broths prepared in repeatedly rewashed glassware sometimes became inhibitory, possibly due to traces of $\mathrm{Na}^{+}$(or detergent residues) in the glass. Therefore plastic containers were used throughout the main experiments, with satisfactory results.

\section{Effects on growth of iron and cysteine}

Three series of doubling dilutions of L-cysteine hydrochloride from 100 to $c .0 .3 \mu \mathrm{g} / \mathrm{ml}$ were prepared in BCYE broth (deficient in both cysteine and iron). Ferric pyrophosphate was added to give a final concentration in one series of $250 \mu \mathrm{g} / \mathrm{ml}$, and in another of $50 \mu \mathrm{g} / \mathrm{ml}$; the third series contained no added iron. Controls were set up as follows: (i) modified BCYE broth without added iron or cysteine; (ii) standard BCYE broth with ferric pyrophosphate $250 \mu \mathrm{g} / \mathrm{ml}$; and (iii) BCYE broth without cysteine but containing ferric pyrophosphate $250 \mu \mathrm{g} / \mathrm{ml}$. The broths $(1 \mathrm{ml})$, inoculated with $10^{6} \mathrm{cfu}$ of an exponential-phase broth culture, were shaken in the MS-2 incubator at $37^{\circ}$ for $30 \mathrm{~h}$.

Growth curves of an isolate of $L$. pneumophila serogroup 1 are shown in fig. 2. The broths containing iron $250 \mu \mathrm{g} / \mathrm{ml}$ in the presence of cysteine $100 \mu \mathrm{g} / \mathrm{ml}$ produced a detectable change in optical density at $9 \mathrm{~h}$, with viable counts at the end of the experiment at $15 \mathrm{~h}$ around $8 \times 10^{9} \mathrm{cfu} / \mathrm{ml}$. These were very similar to the counts obtained with the control broth containing iron $250 \mu \mathrm{g} / \mathrm{ml}$ and cysteine $400 \mu \mathrm{g} / \mathrm{ml}$. There was a marked reduction

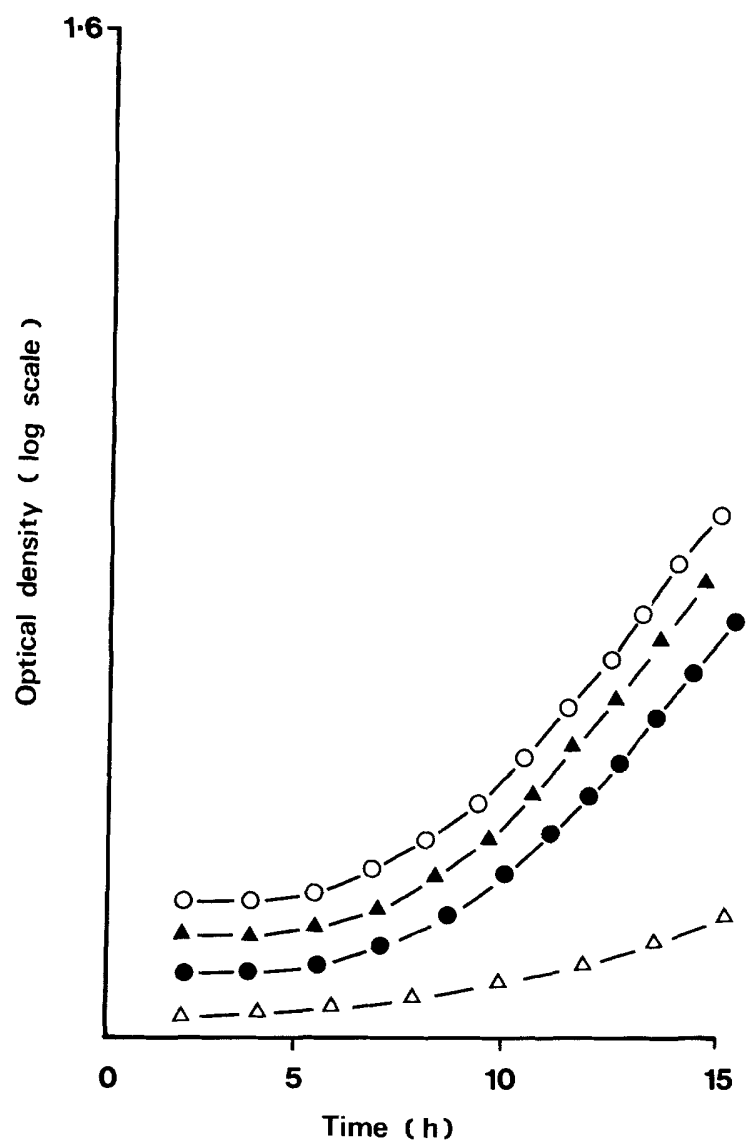

Fig. 2. Effect of iron and cysteine concentration on the growth of L. pneumophila serogroup 1 in BCYE broth inoculated with an exponential-phase culture containing $10^{6} \mathrm{cfu}: \Delta-\Delta$, cysteine $100 \mu \mathrm{g} / \mathrm{ml}$, iron $250 \mu \mathrm{g} / \mathrm{ml} ; \bullet-\bullet$, cysteine $100 \mu \mathrm{g} / \mathrm{ml}$, no iron, $\Delta-\triangle$, cysteine $25 \mu \mathrm{g} / \mathrm{ml}$, iron $250 \mu \mathrm{g} / \mathrm{ml}$; ○—— (cysteine $400 \mu \mathrm{g} / \mathrm{ml}$, iron $250 \mu \mathrm{g} / \mathrm{ml}$ ). The origin of each curve has been expanded up the ordinate limb of the graph for clarity. 
in growth when the cysteine concentration was reduced to $25 \mu \mathrm{g} / \mathrm{ml}$, as shown in fig. 2 (lower curve). $L$. pneumophila did not grow in the control broths without added cysteine and iron, nor in those without cysteine but with iron $250 \mu \mathrm{g} / \mathrm{ml}$.

\section{Discussion}

L. pneumophila is usually difficult to grow in liquid media, especially those heated during preparation (Ristroph et al., 1980) and the latter report recommended filtration in preference to heat-sterilisation. In the present study, legionellae grew best in BCYE broth that had been heat-sterilised but treated with charcoal to neutralise inhibitory substances produced during preparation. Starch and, to a lesser extent, lysed red-blood cells proved effective alternatives to charcoal.

Although inhibitory factors in broth were less after filter-sterilisation than after autoclaving, they were not completely eliminated, because both bacterial counts and opacity readings were considerably lower than those obtained with the charcoaltreated (BCYE) broth, at all points during the incubation period of the tests.

The disadvantage of using charcoal to neutralise inhibitors in broth was the need to remove it to obtain a clear medium for turbidimetric studies. Although difficult to produce, syneresis fluid (YEB 5) is a clear medium which supports a good growth of $L$. pneumophila, probably because it contains adequate nutrients leached from the gel phase.

Oleic acid and other fatty acids suppress the

\section{REFERENCES}

Edelstein P H 198I Improved semi-selective medium for isolation of Legionella pneumophila from contaminated clinical and environmental specimens. Journal of Clinical Microbiology 14:298-303.

Edelstein P H. Meyer R D 1984 Legionnaires' Disease. A Review. Chest 85:114 120.

Greaves P W 1980 New methods for the isolation of Legionella pneumophila. Journal of Clinical Pathology 33:581-584.

Hoffman P S. Pine L 1983 Mechanism of action of charcoal in growth of legionellae but the effect may be neutralised by the addition of starch to the medium (Pine et al., 1979). However, ether extraction of the yeast extract powder only partially reduced the inhibition, suggesting that not all the inhibitors are ethersoluble or that other substances, e.g., superoxides (Hoffman and Pine, 1983), may be involved. Dialysis treatment of yeast extract also had a limited effect in reducing the inhibitory property of the fluid medium, which suggests that substances of different molecular size and diffusibility may be involved. involved.

The omission of iron supplements from BCYE had no effect on the ability of the broth to support the growth of $L$. pneumophila, suggesting that there is sufficient iron in the unsupplemented medium, although we have found that the concentration is $<1 \mu \mathrm{g} / \mathrm{ml}$. However, BCYE broth without cysteine did not support growth of legionellae; although minimal growth was observed with a concentration of $25 \mu \mathrm{g} / \mathrm{ml}$, at least $100 \mu \mathrm{g} / \mathrm{ml}$ appears to be needed for optimal growth.

The reasons for the initial slow bacterial multiplication in these experiments is not clear, but a longer period of adaptation to its environment than is usual amongst the Eubacteriales appears to be necessary before step-up to rapid growth of $L$. pneumophila begins. A means of shortening this long lag phase would greatly facilitate the isolation and study of $L$. pneumophila, but this may be part of the innate biological nature of the organism and not amenable to change.

medium used for culture of Legionella pneumophila. Abstracts of the Annual Meeting of the American Society for Microbiology p 329.

Pine L. George J R, Reeves M W. Harrell W K 1979 Development of a chemically defined liquid medium for growth of Legionella pneumophila. Journal of Clinical Microbiology 9:615-626.

Ristroph J D. Hedlund K W, Allen R G 1980 Liquid medium for growth of Legionella pneumophila. Journal of Clinical Microbiology 11:19-21. 